\title{
Acúmulo de forragem, características morfogênicas e estruturais do capim-marandu sob alturas de pastejo
}

\author{
Herbage accumulation, morphogenetic and structural characteristics in marandu palisadegrass under \\ grazing heights
}

\author{
Cássia Cristina Lemes de Paula ${ }^{\mathrm{I}}$ Valéria Pacheco Batista Euclides ${ }^{\mathrm{II}}$ Beatriz Lempp $^{\mathrm{III}}$ \\ Rodrigo Amorim BarbosaII Denise Baptaglin Montagner ${ }^{\mathrm{II}}$ Marciele Neves Carloto
}

\section{RESUMO}

Os objetivos deste estudo foram avaliar as características morfogennicas e estruturais e o acúmulo de forragem do capim-marandu, submetido a três alturas de pastejo, sob lotação contínua. O delineamento experimental foi de blocos completos casualizados, com duas repetições $e$ três alturas: 15; 30 e $45 \mathrm{~cm}$. O pasto manejado com $15 \mathrm{~cm}$ de altura apresentou as maiores taxa de aparecimento de folhas e densidade de perfilhos basilares. $O$ acúmulo de forragem foi semelhante entre as alturas de pastejo. Com base nas características da planta, o capim-marandu pode ser utilizado entre 15 e $45 \mathrm{~cm}$ de altura do dossel.

Palavras-chave: altura do dossel, Brachiaria brizantha, cerrado, interceptação luminosa.

\section{ABSTRACT}

The objectives of this study were to evaluate the morphological and structural characteristics and the herbage accumulation, in (Brachiaria brizantha cv. 'Marandu') marandu palisadegrass pastures subjected to three grazing heights under continuous stocking. It was used a randomized block design, with two replicates and three sward heights 15, 30 and $45 \mathrm{~cm}$. The biggest leaf appearance and the smallest basal tiller densities decreased were found in $15 \mathrm{~cm}$ pasture The herbage accumulation was similar among the pastures managed with different grazing intensities. The marandu palisadegrass presents high management flexibility, and may be utilized between 15 and $45 \mathrm{~cm}$ sward height.

Key words: Brachiaria brizantha, light interception, savanna, sward height.

\section{INTRODUÇÃO}

As plantas do gênero Brachiaria são caracterizadas pela sua grande flexibilidade de uso e manejo, sendo tolerantes a limitações ou condições que podem ser restritivas para a utilização de um grande número de espécies forrageiras. Os sistemas extensivos de produção predominam no Brasil e estima-se que dos 175 milhões de hectares formados por pastagens cultivadas, $60 \%$ apresentam algum grau de degradação (MACEDO, 2009). A B. brizantha cv. 'Marandu' (capimmarandu) possui grande expressividade na área total de pastagens plantadas, mas, considerando-se o grande percentual de degradação, pode-se inferir que o manejo do pastejo e da pastagem não são adequados ao potencial dessa gramínea.

Segundo Da SILVA \& CORSI (2003), as estratégias de manejo do pastejo visam a manter uma estrutura de dossel na qual a somatória das eficiências dos processos de produção, envolvendo crescimento, utilização e conversão, sejam maximizadas conforme os objetivos específicos de cada sistema. Assim, os estudos sobre ecofisiologia das plantas forrageiras e a ecologia do pastejo são ferramentas importantes de manejo que devem ser incorporados nas avaliações das forrageiras tropicais e auxiliam no entendimento da relação entre solo-planta-animal-meio do sistema. A adoção de alvos de manejo do pastejo, como a altura do dossel, pode ser uma alternativa eficiente para o

IPrograma de Pós-graduação em Ciência Animal, Universidade Federal de Mato Grosso do Sul (UFMS), Campo Grande, MS, Brasil.

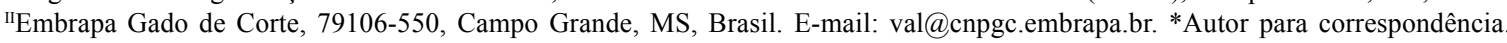
IIIFaculdade de Ciências Agrárias, Universidade Federal da Grande Dourados (UFGD), Dourados, MS. Brasil. 
controle adequado das pastagens, e também se constitui em ferramenta facilmente adotável pelos produtores.

É necessário conhecer o comportamento e os limites de cada espécie e cultivar, de acordo com a disponibilidade de recurso do meio, como fertilidade do solo, temperatura e precipitação. Assim, a recomendação de alturas de pastejo pode ser variável com as condições do meio para uma mesma espécie ou cultivar. Este estudo teve por objetivo obter informações acerca das características morfofisiológicas de pastos de capimmarandu, com base nas características morfogênicas e estruturais do pasto e no acúmulo de forragem manejado sob três alturas de pastejo.

\section{MATERIAL E MÉTODOS}

O experimento foi realizado na Embrapa Gado de Corte, Campo Grande, MS, de janeiro a dezembro de 2008. O capim-marandu foi estabelecido em novembro de 2000 e, desde novembro de 2005, é manejado com as mesmas alturas de pastejo. A precipitação pluvial e a temperatura, registradas no período experimental, foram utilizadas para o cálculo do balanço hídrico. A capacidade de armazenamento de água do solo (CAD) foi de $75 \mathrm{~mm}$ (Figura 1).

O solo é o da classe Latossolo Vermelho Distrófico, cuja análise química apresentou os seguintes resultados: 5,0pH $\left(\mathrm{CaCl}_{2}\right) ; 35 \%$ de saturação por bases; 3,7\% de saturação por alumínio; 3,7\% matéria orgânica; 1,6mg dm${ }^{-3} \mathrm{P}$ (Mehlich 1); e 46,9 $\mathrm{mg} \mathrm{dm}^{-3} \mathrm{~K}$ (Mehlich 1). Em janeiro de 2008, foi feita a adubação de manutenção com $200 \mathrm{~kg} \mathrm{ha}^{-1}$ da fórmula 0-20-20. Aplicou-se $100 \mathrm{~kg} \mathrm{ha}^{-1} \mathrm{de} \mathrm{N}$, na forma de ureia, divididos em dois períodos, novembro de 2007 e março de 2008; e $600 \mathrm{~kg} \mathrm{ha}^{-1}$ de gesso agrícola em abril de 2008.
A área experimental possuía quatro hectares, divididos em seis piquetes de 0,67 ha. $\mathrm{O}$ método de pastejo foi o de lotação contínua com taxa de lotação variável. O delineamento experimental foi o de blocos casualizados com três tratamentos e duas repetições. Os tratamentos foram alturas de pastejo de 15, 30 e $45 \mathrm{~cm}$. O monitoramento da altura dos pastos, média da curvatura das folhas superiores em torno da régua, foi realizado duas vezes por semana, medindo-se 80 pontos aleatórios por piquete.

As variáveis morfogênicas e estruturais foram estimadas por meio de 50 perfilhos marcados, divididos em cinco pontos, por piquete. A avaliação foi feita em meses alternados, em períodos de 28 dias. Duas vezes por semana, foi mensurado o comprimento das lâminas foliares expandidas, em expansão e em senescência, o comprimento do colmo (altura do solo até a lígula da última folha expandida), o aparecimento das folhas novas surgidas e a ocorrência de pastejo. Foram calculadas as taxas de aparecimento e alongamento de folhas, alongamento de colmo, senescência de folhas, comprimento final da folha, número de folhas verdes e duração de vida das folhas, de acordo com metodologia proposta por LEMAIRE \& CHAPMAN (1996).

As densidades populacionais de perfilhos basilares, aéreos e reprodutivos foram obtidas, a cada 28 dias, por meio de contagem, em oito áreas fixas de $0,25 \mathrm{~m}^{2}(100 \times 25 \mathrm{~cm})$ em cada piquete. A dinâmica do perfilhamento foi determinada pela marcação dos perfilhos em uma área de $0,06 \mathrm{~m}^{2}(0,25 \mathrm{mx} 0,25 \mathrm{~m})$ com fios coloridos, utilizando-se uma cor distinta a cada geração. Foram contabilizados os perfilhos basilares e aéreos de cada geração, estimando-se suas taxas de

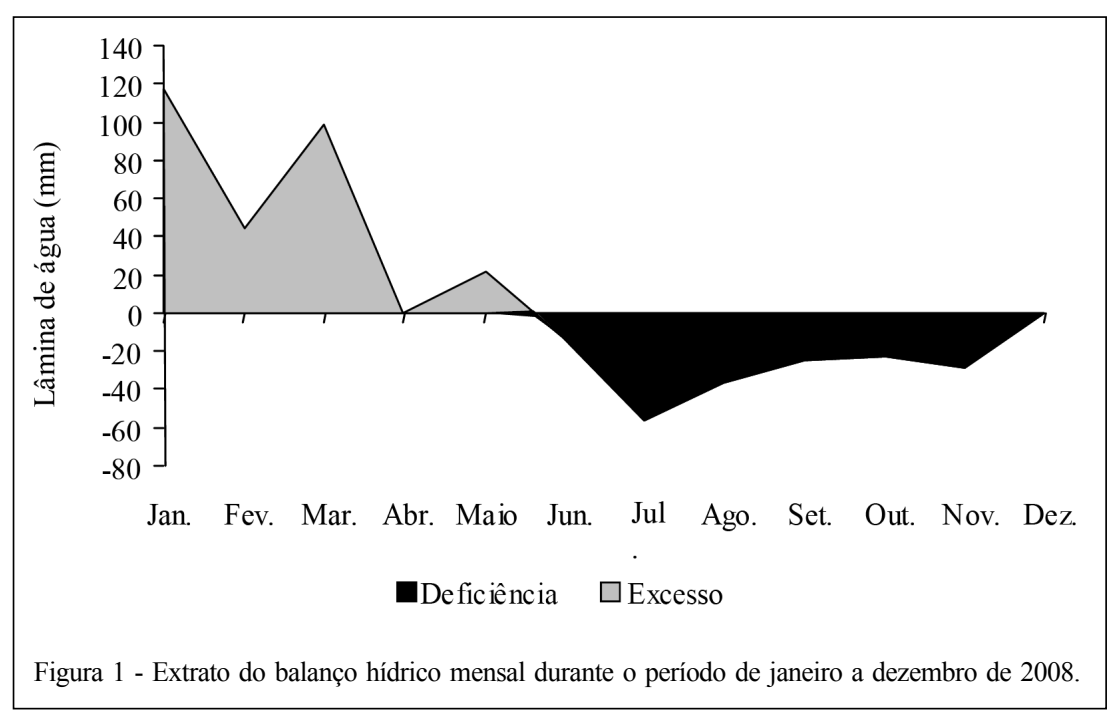

Ciência Rural, v.42, n.11, nov, 2012. 
aparecimento e mortalidade. O índice de estabilidade da população de perfilhos basilares foi calculado de acordo com BAHMANI et al. (2003).

O monitoramento da interceptação de luz e a estimativa do índice de área foliar foi realizado a cada 15 dias, utilizando o aparelho analisador de dossel (AccuPAR Linear PAR/LAI ceptometer, Model PAR80) em 60 estações de leitura por unidade experimental. Em cada estação de leitura, foi realizada uma leitura acima do dossel e outra no nível do solo.

A massa de forragem foi estimada a cada 28 dias, cortando-se 15 amostras ao acaso de $1 \mathrm{~m}^{2}$ por piquete, rente ao solo. Elas foram secas a $55^{\circ} \mathrm{C}$, em estufa de ar forçado até peso constante, e pesadas. Para estimativa do acúmulo de forragem, utilizaram-se três gaiolas de exclusão de $1 \mathrm{~m}^{2}$, por piquete, realocadas a cada 28 dias, seguindo-se a metodologia do triplo emparelhamento (MANNETJE, 1978).

Os dados foram agrupados por estação (verão, outono, inverno e primavera) e analisados por um modelo matemático, contendo o efeito aleatório de bloco, os efeitos fixos de altura do dossel, estações do ano e as interações entre eles. As análises foram feitas pelo método dos quadrados mínimos, utilizando-se o procedimento General Linear Model, disponível no SAS Institute (1996). Os comandos RANDON e TEST foram usados para a identificação e realização dos testes apropriados para cada variável dependente. A comparação de médias foi realizada pelo teste de Tukey adotando-se $5 \%$ de probabilidade.

\section{RESULTADOS E DISCUSSÃO}

As alturas reais médias dos pastos foram $14,6( \pm 1,3) ; 28,8( \pm 2,2)$ e $42,1( \pm 3,7)$, respectivamente, para 15,30 e $45 \mathrm{~cm}$. Não foi observada interação $(\mathrm{P}>0,05)$ entre alturas e estações do ano para as variáveis estudadas. A maior taxa de aparecimento de folhas (TApF) ocorreu nos pastos manejados a $15 \mathrm{~cm}$ e foi similar entre os pastos de 30 e $45 \mathrm{~cm}$ (Tabela 1). A TApF possui papel determinante nas características estruturais do dossel, pois interfere no tamanho da folha, na densidade de perfilhos e no número de folhas por perfilho (LEMAIRE \& CHAPMAN, 1996). Segundo SBRISSIA (2004), plantas mantidas mais altas apresentam bainhas com comprimentos maiores, o que poderia explicar o maior número de dias requerido para o aparecimento de folhas nos pastos com maior altura de pastejo ( $30 \mathrm{e} 45 \mathrm{~cm}$ ), pois as folhas novas que surgem em um perfilho, comumente, localizam-se em níveis de inserção cada vez mais altos, e a distância a ser percorrida pela folha do meristema até a extremidade do pseudocolmo é maior. A taxa de alongamento de folhas (TAlF) foi maior $(\mathrm{P}=0,0035)$ nos pastos manejados a $45 \mathrm{~cm}$ e semelhante em 30 e $15 \mathrm{~cm}$ (Tabela 1). As maiores TApF e TAlF foram observadas no verão e as menores no inverno (Tabela 2), reflexo do balanço hídrico positivo, entre temperatura e precipitação (Figura 1), e da adubação nitrogenada realizada no verão. A relação entre a TAlF e TApF

Tabela 1 - Médias, erros-padrão (EPM) e níveis de significância (P) para as taxas de aparecimento de folhas (TApF), de alongamento de folhas (TAlF) e de alongamento de colmo (TAlC), taxa de senescência de folhas (TSeF), comprimentos finais da folha inteira (CFFint), da folha pastejada (CFFpast) e do colmo (CFC), e densidades populacionais de perfilhos basilares (DPPb), aéreos $(\mathrm{DPPa})$ e reprodutivo (DPPr), massa seca total (MST), índice de área foliar (IAF), interceptação luminosa (IL) em pastos de capim-marandu sob lotação contínua.

\begin{tabular}{|c|c|c|c|c|c|}
\hline \multirow{2}{*}{ Variáveis } & & tura $(\mathrm{cm})$ & & \multirow{2}{*}{ EPM } & \multirow{2}{*}{$\mathrm{P}$} \\
\hline & 15 & 30 & 45 & & \\
\hline TApF (folha perfilho ${ }^{-1} \mathrm{dia}^{-1}$ ) & $0,055 \mathrm{a}$ & $0,044 b$ & $0,046 b$ & 0,0016 & 0,0035 \\
\hline TAlF (cm perfilho ${ }^{-1} \mathrm{dia}^{-1}$ ) & $0,511 b$ & $0,580 \mathrm{~b}$ & $0,761 \mathrm{a}$ & 0,0510 & 0,0185 \\
\hline TAlC $\left(\mathrm{cm}\right.$ perfilho $\left.{ }^{-1} \mathrm{dia}^{-1}\right)$ & $0,003 b$ & $0,048 \mathrm{ab}$ & $0,074 \mathrm{a}$ & 0,0158 & 0,0315 \\
\hline $\mathrm{TSeF}\left(\mathrm{cm} \mathrm{dia}{ }^{-1}\right)$ & $0,095 b$ & $0,232 \mathrm{ab}$ & $0,271 \mathrm{a}$ & 0,044 & 0,0409 \\
\hline CFFint $(\mathrm{cm})$ & $11,0 \mathrm{c}$ & $17,7 \mathrm{~b}$ & $20,7 a$ & 0,5315 & 0,0001 \\
\hline CFFpast (cm) & $4,3 \mathrm{c}$ & $7,6 \mathrm{~b}$ & $11,5 \mathrm{a}$ & 0,7111 & 0,0002 \\
\hline $\mathrm{CFC}(\mathrm{cm})$ & $8,0 \mathrm{~b}$ & $20,1 \mathrm{a}$ & $27,6 a$ & 2,4340 & 0,0010 \\
\hline $\mathrm{DPPb}$ (perfilhos $\mathrm{m}^{-2}$ ) & $973 a$ & $759 b$ & $634 \mathrm{c}$ & 29,6 & 0,0001 \\
\hline DPPa (perfilhos $\mathrm{m}^{-2}$ ) & $62 b$ & $101 \mathrm{a}$ & $101 \mathrm{a}$ & 8,4 & 0,0001 \\
\hline DPPr (perfilhos $\mathrm{m}^{-2}$ ) & $20 \mathrm{~b}$ & $44 \mathrm{a}$ & $36 \mathrm{ab}$ & 6,3 & 0,0441 \\
\hline $\operatorname{MST}\left(\mathrm{kg} \mathrm{ha}^{-1}\right.$ de MS) & $3.187 \mathrm{c}$ & $6.098 b$ & $7.753 a$ & 250 & 0,0001 \\
\hline IAF & $2,0 \mathrm{~b}$ & $3,2 \mathrm{a}$ & $4,3 \mathrm{a}$ & 0,29 & 0,0001 \\
\hline IL (\%) & $58,1 \mathrm{c}$ & $81,3 b$ & $87,8 \mathrm{a}$ & 1,73 & 0,0001 \\
\hline
\end{tabular}

Médias com letras distintas na mesma linha diferem entre si pelo teste Tukey $(\mathrm{P}<0,05)$.

Ciência Rural, v.42, n.11, nov, 2012. 
Tabela 2 - Médias, erros-padrão (EPM) e níveis de significância (P) para as taxas de aparecimento de folhas (TApF), de alongamento de folhas (TAlF) e de alongamento de colmo (TAlC), número de folhas vivas (NFV) e em expansão (NFE), duração de vida das folhas (DVF) e densidades populacionais de perfilhos basilares (DPPb), aéreos (DPPa) e reprodutivo (DPPr) em pastos de capimmarandu sob lotação contínua, de acordo com as estações do ano.

\begin{tabular}{|c|c|c|c|c|c|c|}
\hline \multirow{2}{*}{ Variáveis } & \multirow[b]{2}{*}{ Verão } & \multirow[b]{2}{*}{ Outono } & \multirow[b]{2}{*}{ Inverno } & \multirow[b]{2}{*}{ Primavera } & \multirow{2}{*}{ EPM } & \multirow{2}{*}{$\mathrm{P}$} \\
\hline & & & & & & \\
\hline TApF (folha perfilho ${ }^{-1} \mathrm{dia}^{-1}$ ) & $0,073 a$ & $0,045 b$ & $0,028 \mathrm{c}$ & $0,047 \mathrm{~b}$ & 0,0019 & $<0,0001$ \\
\hline TAlF (cm perfilho ${ }^{-1}$ dia $^{-1}$ ) & $1,052 \mathrm{a}$ & $0,455 \mathrm{c}$ & $0,298 \mathrm{c}$ & $0,663 b$ & 0,0589 & $<0,0001$ \\
\hline TAlC $\left(\mathrm{cm}\right.$ perfilho $\left.{ }^{-1} \mathrm{dia}^{-1}\right)$ & $0,08 \mathrm{a}$ & $0,06 \mathrm{a}$ & $0,01 b$ & $0,03 \mathrm{ab}$ & 0,0183 & 0,0413 \\
\hline NFV (folha perfilho ${ }^{-1}$ ) & $5,0 \mathrm{a}$ & $4,1 \mathrm{~b}$ & $2,8 \mathrm{c}$ & $3,7 b$ & 0,1530 & 0,0001 \\
\hline NFE (folha perfilho ${ }^{-1}$ ) & $2,0 \mathrm{ab}$ & $1,9 b$ & $1,6 \mathrm{c}$ & $2,1 \mathrm{a}$ & 0,06 & 0,0001 \\
\hline DVF (dias) & $69 c$ & $93 \mathrm{ab}$ & $101 \mathrm{a}$ & $83 \mathrm{bc}$ & 13,3 & 0,0101 \\
\hline $\mathrm{DPPb}\left(\right.$ perfilhos $\mathrm{m}^{-2}$ ) & $849 \mathrm{ab}$ & $959 a$ & $604 c$ & $744 b$ & 50 & 0,0001 \\
\hline DPPa (perfilhos $\mathrm{m}^{-2}$ ) & $69 b$ & $150 \mathrm{a}$ & $64 b$ & $70 \mathrm{~b}$ & 13,2 & 0,0001 \\
\hline DPPr (perfilhos $\mathrm{m}^{-2}$ ) & $17 b$ & $84 a$ & $24 b$ & $8 b$ & 9,9 & 0,0001 \\
\hline
\end{tabular}

Médias com letras distintas na mesma linha diferem entre si pelo teste Tukey $(\mathrm{P}<0,05)$.

determina o comprimento final da folha inteira (CFFint). Neste estudo, o CFFint decresceu, à medida que diminuiu a altura do dossel (Tabela 2), concordando com as observações de NABINGER \& PONTES (2001), de que TAlF está diretamente correlacionada ao tamanho final da folha, e as de menor tamanho estão associadas à alta TApF. LEMAIRE \& CHAPMAN (1996) citam que CFF é uma característica plástica responsiva à intensidade de desfolhação, podendo ser uma estratégia morfológica de escape da planta ao pastejo. O comprimento de folha inteira, quando comparado com as pastejadas, aliado ao comprimento do colmo, pode levar a estimativa da facilidade encontrada pelo animal no pastejo. Nos pastos manejados a 15 e $30 \mathrm{~cm}$, em torno de $40 \%$ do comprimento total da lâmina foi pastejada, enquanto, nos de $45 \mathrm{~cm}$, esse valor foi de 55\%. Esses resultados são semelhantes aos observados por LACA et al. (1992) para pastagens temperadas, indicando que $50 \%$ do tamanho total da folha é removido em cada bocado, sugerindo que essa proporção também pode ser obtida em pastos tropicais.

A duração de vida da folha (DVF) não diferiu entre alturas $(\mathrm{P}=0,0625)$, mas foi maior no inverno, menor no verão e intermediária nas demais estações (Tabela 2). À medida que a planta reduziu a TApF, houve acréscimos na DVF para manutenção de NFV ao longo do ano, que de acordo com LEMAIRE \& CHAPMAN (1996), é uma compensação pelo decréscimo da TApF, evidenciando o mecanismo das plantas perenes de tentar manter o número de folhas verdes ao longo do ano. A taxa de senescência da folha (TSeF) foi maior em pastos mantidos a $45 \mathrm{~cm}$, menor em
$15 \mathrm{~cm}$ e intermediária em $30 \mathrm{~cm}$. Não foi observada diferença $(\mathrm{P}=0,1487)$ para a TSeF entre as estações do ano. A semelhança na TSeF entre as estações mostra que o pasto de capim-marandu está em equilíbrio. Segundo NABINGER \& PONTES (2001), quando um perfilho atinge seu número máximo de folhas vivas, passa a haver um equilíbrio entre a taxa de aparecimento de folhas e a senescência de folhas que alcançaram o seu período de duração de vida. Por outro lado, esse equilíbrio não foi alcançado entre as alturas de manejo, o que evidencia um potencial comprometimento dos pastos manejados a $45 \mathrm{~cm}$ de altura.

$\mathrm{O}$ número de folhas verdes por perfilho (NFV) foi similar $(\mathrm{P}=07424)$ entre as alturas com média $3,9( \pm 0,1)$ folhas perfilho ${ }^{-1}$. O NFV que é resultante do produto entre a TApF e a DVF e, na ausência de deficiências nutricionais, é característica geneticamente estável, portanto, pouco influenciada pelo manejo (NABINGER \& PONTES, 2001). Em relação às estações do ano, o NFV apresentou o mesmo comportamento da TApF, ou seja, condições do meio limitantes (Figura 1) diminuíram a TApF, resultando em redução no número de folhas em expansão por perfilho (Tabela 2), contribuindo para o decréscimo no NFV.

A taxa de alongamento do colmo (TAlC) foi maior para o pasto mantido a $45 \mathrm{~cm}$ em relação a $15 \mathrm{~cm}$ (Tabela 2), consequentemente, o comprimento final do colmo (CFC) foi menor para o pasto mantido mais baixo (Tabela 1). Pastos mantidos mais altos apresentam maior fluxo de desenvolvimento, consequência de maiores comprimentos de folha verde e do perfilho (SBRISSIA\& Da SILVA, 2001). A maior altura de manejo $(45 \mathrm{~cm})$ promove o aumento do alongamento do entrenó, 
constituindo-se em capacidade adaptativa da planta a altura de manejo, a qual busca alcançar o topo do dossel, interceptando maior quantidade de luz solar incidente. As TAlC foram maiores no verão e outono, menores no inverno, e intermediárias na primavera (Tabela 2), consequência provável das condições do meio, favorecendo o desenvolvimento da planta. No outono, a maior TAlC pode ser consequência do pico de florescimento do capim-marandu, visto o número de perfilhos reprodutivos encontrados nesta estação (Tabela 2). Apesar das diferenças observadas para a TAlC, o CFC foi semelhante, sendo a média e seu erropadrão de $18,6( \pm 2,8) \mathrm{cm}$.

Houve decréscimos na densidade populacional de perfilhos basilares (DPPb) à medida que se aumentou a altura do pasto (Tabela 1). A área foliar é controlada pela intensidade de pastejo (MATTHEW et al., 2001) e determina a qualidade da radiação na base do dossel que pode ativar gemas axilares gerando novos perfilhos (DEREGIBUS et al., 1983). O decréscimo na DPPb verificado com a menor altura de pastejo está associado à competição entre os perfilhos, já que a quantidade de luz incidente na base do dossel $(\mathrm{P}=0,0001)$ foi de 544,240 e $137 \mu \mathrm{Mol} \mathrm{m}^{-2} \mathrm{~s}^{-1}$, para 15,30 e $45 \mathrm{~cm}$, respectivamente.

A taxa de aparecimento ( $\mathrm{TAPb} ; \mathrm{P}=0,9303$ ), de mortalidade (TMPb; $\mathrm{P}=0,7401)$ e o índice de estabilidade (IEst; $\mathrm{P}=0,7275$ ) de perfilhos basilares foram semelhantes entre as alturas de manejo, sendo as médias e erros-padrão, respectivamente, de 0,91 $( \pm 0,14)$ e $0,13( \pm 0,03)$ e $1,66( \pm 0,10)$ perfilhos perfilho $^{-1}$ $\mathrm{dia}^{-1}$. Independentemente da altura pastejada, o IEst foi superior a 1, que, segundo BAHMANI et al. (2003), indica a compensação da TMP pela TAP e que estes pastos encontram-se com a população de perfilhos estável, após três anos de pastejo.

Não foram observadas diferenças para as taxas de aparecimento (TAPa; $\mathrm{P}=0,8324$ ) e de mortalidade (TMPa; $\mathrm{P}=0,8874)$ dos perfilhos aéreos entre as alturas de pastejo, sendo de $0,98( \pm 0,14)$ e 0,22 $( \pm 0,04)$ perfilhos.perfilho ${ }^{-1} \mathrm{dia}^{-1}$, respectivamente.

Muitos fatores afetam o perfilhamento das forrageiras, dentre eles LANGER (1979) cita que a produção de perfilhos é controlada pela água, luz, temperatura e nutrientes, principalmente nitrogênio e, em menor escala, fósforo e potássio, além do estágio de desenvolvimento da planta. A interação desses fatores determina o aparecimento e a morte de perfilhos. As maiores $\mathrm{TAPb}$ ocorreram no verão e primavera, enquanto maior TMPb no inverno e primavera. No verão, também ocorreu maior TAPa e IEst e menor TMPa (Tabela 3 ).

Acréscimos na massa seca total (MST) ocorreram à medida que se aumentou a altura de pastejo (Tabela 1), consequência do decréscimo nas taxas de lotação necessárias para manter as alturas do dossel pretendidas, de 2,8; 2,5 e 2,0 $\mathrm{UA} \mathrm{ha}^{-1}$, respectivamente, para 15,30 e $45 \mathrm{~cm}$ (PAULA et al., 2012). Apesar do decréscimo na DPP, à medida que aumentou a altura do dossel (Tabela 1), o acúmulo de forragem foi similar $(\mathrm{P}=0,7187)$, sendo, em média, de $63( \pm 12) \mathrm{kg} \mathrm{ha}^{-1} \mathrm{dia}^{-1} \mathrm{de}$ MS. Esse fato pode ser explicado pela compensação entre tamanho e densidade populacional de perfilhos em comunidades de plantas (SBRISSIA \& Da SILVA, 2008a). Essa compensação pode fazer com que grandes

Tabela 3 - Médias, erros-padrão (EPM) e níveis de significância (P) para as taxas de aparecimento de perfilhos basilares e aéreos (TAPb; TAPa, perfilho perfilhos ${ }^{-1} 30$ dias $\left.^{-1}\right)$, taxas de mortalidade de perfilhos basilares e aéreos (TMPb; TMPa, perfilho perfilhos ${ }^{-1} 30$ $\operatorname{dias}^{-1}$ ) e índice de estabilidade (IEst, perfilho perfilhos ${ }^{-1} 30$ dias $^{-1}$ ), massa seca total (MST, $\mathrm{kg} \mathrm{ha}^{-1}$ de MS), taxa de acúmulo de forragem (TAF, kg.ha-1 $\mathrm{dia}^{-1}$ ), índice de área foliar (IAF) e interceptação luminosa (IL, \%), de acordo com as estações do ano em capim-marandu sob lotação contínua.

\begin{tabular}{|c|c|c|c|c|c|}
\hline \multirow{2}{*}{ Variáveis } & \multirow[b]{2}{*}{ Verão } & \multirow[b]{2}{*}{ Outono } & \multirow[b]{2}{*}{ Inverno } & \multirow[b]{2}{*}{ Primavera } & \multirow{2}{*}{$\mathrm{P}$} \\
\hline & & & & & \\
\hline $\mathrm{TAPb}$ & $1,42 \mathrm{a}(0,19)$ & $1,04 \mathrm{ab}(0,15)$ & $0,81 \mathrm{ab}(0,09)$ & $0,77 \mathrm{~b}(0,11)$ & 0,0256 \\
\hline $\mathrm{TMPb}$ & $0,05 \mathrm{~b}(0,03)$ & $0,11 \mathrm{ab}(0,03)$ & $0,17 \mathrm{a}(0,02)$ & $0,12 \mathrm{ab}(0,02)$ & 0,0325 \\
\hline IEst & $2,3 a(0,15)$ & $1,8 \mathrm{~b}(0,12)$ & $1,5 \mathrm{c}(0,09)$ & 1,6 bc $(0,07)$ & 0,0006 \\
\hline $\mathrm{TAPa}$ & $1,92 \mathrm{a}(0,21)$ & $1,07 \mathrm{~b}(0,17)$ & $0,87 \mathrm{~b}(0,11)$ & $0,70 \mathrm{~b}(0,12)$ & 0,0003 \\
\hline TMPa & $0,08 \mathrm{~b}(0,06)$ & $0,21 \mathrm{ab}(0,05)$ & $0,27 \mathrm{a}(0,03)$ & $0,22 \mathrm{a}(0,03)$ & 0,0425 \\
\hline MST & 5.988 a $(280,2)$ & $6.394 \mathrm{a}(343,2)$ & $5.188 \mathrm{~b}(280,5)$ & $5.149 \mathrm{~b}(242,7)$ & 0,0877 \\
\hline TAF & $112,0 \mathrm{a}(13,23)$ & $56,7 \mathrm{~b}(13,23)$ & $-17,0 \mathrm{c}(15,57)$ & $79,5 \mathrm{ab}(14,21)$ & 0,0004 \\
\hline IAF & 3,6 a $(0,25)$ & - & $2,3 \mathrm{~b}(0,31)$ & $3,7 \mathrm{a}(0,31)$ & 0,0059 \\
\hline IL & $81,5 \mathrm{a}(1,5)$ & - & $69,5 \mathrm{c}(1,83)$ & $76,2 \mathrm{~b}(1,83)$ & 0,0001 \\
\hline
\end{tabular}

Médias com letras distintas na mesma linha diferem entre si pelo teste Tukey $(\mathrm{P}<0,05)$.

Valores entre parênteses representam o erro-padrão da média. 
variações entre regimes de desfolhação resultem em apenas pequenas diferenças no acúmulo de forragem.

$O$ índice de área foliar (IAF) foi maior para os pastos com 30 e $45 \mathrm{~cm}$ do que a $15 \mathrm{~cm}$ de altura (Tabela 1 ). Assim, a interceptação luminosa (IL) decresceu, à medida que diminuiu a altura do pasto (Tabela 1), resultado esperado, uma vez que, quanto maior o IAF, maior a capacidade de a forragem interceptar a radiação que incide no dossel. A IL foi mais baixa do que aquelas encontradas, para o capim-marandu sob lotação contínua, por MOLAN (2004), que observou que, a partir de $20 \mathrm{~cm}$, a IL do dossel era de $98 \%$. Sob pastejo intermitente, TRINDADE et al. (2007) registraram 95\% e $98 \%$ de IL, respectivamente, para as alturas de 24 e $32 \mathrm{~cm}$, em capim-marandu. Provavelmente, a maior IL com menores alturas dos dosséis encontradas por esses autores foi consequência da elevada fertilidade natural do solo e da maior adubação nitrogenada utilizada, que foram, respectivamente, de 167 e $190 \mathrm{~kg}$ ha $^{-1}$ de N; resultando, possivelmente, em estruturas diferentes dos dosséis.

$\mathrm{O}$ IAF foi menor no inverno em relação às demais estações (Tabela 3). VERHANGEN et al. (1963) citam vários aspectos envolvidos na IL, como a organização espacial e ângulo foliar, idade, tipo e tamanho das folhas, saturação luminosa, flutuações na IL e qualidade da luz. Assim, o IAF explica parcialmente a IL pelo dossel forrageiro e, de acordo SBRISSIA \& Da SILVA (2008b), o uso do IAF estimado pelo aparelho analisador de dossel deve ser utilizado com cautela. Apesar de IAF semelhantes no verão e na primavera, a IL foi maior no verão, seguido da primavera e do inverno (Tabela 3). Nesse caso, o IAF, provavelmente, não estava relacionado apenas com a área foliar, mas também com a quantidade e com o posicionamento de outras partes da planta no interior do dossel.

A TAF foi maior no verão, seguida da primavera, outono e inverno (Tabela 3). Das características morfogênicas, a que mais influenciou no acúmulo de forragem foi a TApF (Tabela 2). Embora com maior TAF no verão, as MST foram semelhantes entre o verão e o outono (Tabela 3 ), o que pode ser explicado pela maior taxa de lotação utilizada no verão $\left(2,1 \mathrm{UA} \mathrm{ha}^{-1}\right)$, quando comparada ao outono $\left(1,8 \mathrm{UA} \mathrm{ha}^{-1}\right)$.

\section{CONCLUSÃO}

O capim-marandu apresenta grande flexibilidade de manejo, podendo ser utilizado entre 15 e $45 \mathrm{~cm}$ de altura do dossel. As características morfogênicas e estruturais do capim-marandu são altamente influenciadas pela estação do ano.

\section{AGRADECIMENTOS}

À Fundação de Apoio ao Desenvolvimento do Ensino, Ciência e Tecnologia do Estado de Mato Grosso do Sul (Fundect) e Embrapa Gado de Corte, pelo financiamento do projeto. À FUNDECT, pelo financiamento parcial do experimento e pelas bolsas de mestrado da primeira e sexta autoras. Ao Conselho Nacional de Desenvolvimento Científico e Tecnológico (CNPq), pela bolsa de pesquisa da segunda e terceira autoras, e de Desenvolvimento Científico Regional da quinta autora.

\section{REFERÊNCIAS}

BAHMANI, I. et al. Tiller dynamics of perennial ryegrass cultivars derived from different New Zealand ecotypes: effects of cultivars, season, nitrogen fertilizer, and irrigation. Australian Journal of Agricultural Research, v.54, n.8, p.803-817, 2003.

DA SILVA, S.C.; CORSI, M. Manejo do pastejo. In: SIMPÓSIO SOBRE MANEJO DE PASTAGEM, 20., 2003, Piracicaba, SP. Anais... Piracicaba: FEALQ, 2003. p.155-186.

DEREGIBUS, V.A. et al. Effects of light quality on tiller production in Lolium spp. Plant Physiology, v.72, n.3, p.900902, 1983.

LACA, E.A. et al. Effects of sward height and bulk density on bite dimensions of cattle grazing homogeneous swards. Grass and Forage Science, v.47, p.91-103, 1992.

LANGER, R.H.M. Tillering. In: LANGER, R.H.M. (Ed). How grasses grow. London: Edward Arnold, 1979. Cap.5, p.19-25.

LEMAIRE, G.; CHAPMAN, D. Tissue flows in grazed plant communities. In: HODGSON, J.; ILLIUS A.W. (Ed.). The ecology and management of grazing systems. London: CAB International, 1996. Cap.1, p.3-36.

MACEDO, M.C.M. Integração lavoura e pecuária: o estado da arte e inovações tecnológicas. Revista Brasileira de Zootecnia, v.38, p.133-146, 2009 (supl. especial). Disponível em: $<$ http:// www.scielo.br/scielo.php?script $=$ sci_arttext\&pid $=$ S $1516-$ $35982009001300015 \& \operatorname{lng}=\mathrm{en} \& \mathrm{nrm}=\mathrm{iso}>$. Acesso em: 9 maio, 2012. doi: 10.1590/S1516-35982009001300015.

MANNETJE, L.'t. Measuring quantity of grassland vegetation. In: ___ (Ed.). Measurement of grassland vegetation and animal production. Bucks: CAB, 1978. p.63-95. (Bulletin, 52).

MATTHEW, C. et al. Understanding shoot and root development. In: GOMIDE, J.A. (Ed.). Proceedings of the XIX International Grassland Congress. Piracicaba: FEALQ, 2001. p.19-27.

MOLAN, L.K. Estrutura do dossel, interceptação luminosa e acúmulo de forragem em pastos de capimMarandu submetidos a alturas de pastejo por meio de lotação contínua. 2004. 180f. Dissertação (Mestrado em Agronomia) - Escola Superior de Agricultura "Luiz de Queiroz"/ Universidade de São Paulo, Piracicaba, SP. 
NABINGER, C.; PONTES, L.S. Morfogênese de plantas forrageiras e estrutura do pasto. In: REUNIÃO ANUAL DA SOCIDADE BRASILEIRA DE ZOOTECNIA, 38., 2001, Piracicaba, SP. Anais... Piracicaba: SBZ, 2001. p.755-771.

PAULA, C.C.L. et al. Estrutura do dossel, consumo e desempenho animal em pastos de capim-marandu sob lotação contínua. Arquivo Brasileiro de Medicina Veterinária e Zootecnia, v.64, n.1, p.169-176, 2012. Disponível em: <http:/ /www.scielo.br/pdf/abmvz/v64n1/a24v64n1.pdf >. Acesso em: 20 jun. 2012. doi: 10.1590/S0102-09352012000100024

SAS INSTITUTE. User software: changes and enhancements through release. Version 6.11. Cary, 1996. 1014p.

SBRISSIA, A.F. Morfogênese, dinâmica do perfilhamento e do acúmulo de forragem em pastos de capim-marandu sob lotação contínua. 2004. 171f. Tese (Doutorado em Agronomia) - Escola Superior de Agricultura "Luiz de Queiroz"/ Universidade de São Paulo, Piracicaba, SP

SBRISSIA, A.F.; DA SILVA, S.C. Compensação tamanho/densidade populacional de perfilhos em pastos de capim-marandu. Revista Brasileira de Zootecnia, v.37, p.35-47, 2008a. Disponível em: $<$ http://www.scielo.br/scielo.php?script=sci_arttext\&pid=S1516- 35982008000100005\&lng=pt\&nrm=iso $>$. Acesso em: 23 mar. 2011. doi: $10.1590 / \mathrm{S} 1516-35982008000100005$.

SBRISSIA, A.F.; Da SILVA, S.C. O ecossistema de pastagens e a produção animal. In: REUNIÃO ANUAL DA SOCIDADE BRASILEIRA DE ZOOTECNIA, 38., 2001, Piracicaba, SP. Anais... Piracicaba: Sociedade Brasileira de Zootecnia, 2001. p.731-754.

SBRISSIA, A.F.; DA SILVA, S.C. Comparação de três métodos para a estimativa do índice de área foliar em pastos de capimmarandu sob lotação contínua. Revista Brasileira de Zootecnia, v.37, p.212-220, 2008b. Disponível em: $<$ http:// www.scielo.br/scielo.php? script $=$ sci_arttext\&pid $=\mathrm{S} 1516$ $35982008000200003 \& \operatorname{lng}=$ pt\&nrm $=$ iso $>$. Acesso em: 23 mar. 2011. doi: 10.1590/S1516-35982008000200003.

TRINDADE, J.K. et al. Composição morfológica da forragem consumida por bovinos de corte durante o rebaixamento do capimmarandu submetido a estratégias de pastejo rotativo. Pesquisa Agropecuária Brasileira, v.42, p.883-890, 2007. Disponível em: $<$ http://www.scielo.br/scielo.php?script=sci arttext\&pid=S0100204X2007000600016\&lng=pt\&nrm=isso $>$. Acesso em: 20 mar. 2011. doi: 10.1590/S0100-204X2007000600016.

VERHANGEN, A.M.W. et al. Plant production in relation to foliage illumination. Annals of Botany, v.27, p.626-640. 1963. 